\title{
Variation in the Distribution of Nerves in the Front of Arm- A Cadaveric Study from South India
}

\begin{abstract}
Introduction: Brachial plexus are the main nerve supply to the muscles of upper limb and the muscles of the flexor compartment arm are supplied by Musculocutaneous Nerve (McN). Any variations in the nerve innervation of the flexor muscles of arm should be documented as they have clinical implications.

Aim: To observe and document the variations in the innervation of muscles of the front of arm and discuss its clinical implications with the help of available literature.

Materials and Methods: This cross-sectional descriptive study was done in the Department of Anatomy, Siddhartha Medical College for a period of three years that is from October 2017 to October 2020 on 50 upper limbs, from 25 cadavers. The upper limbs were dissected to observe the innervations of muscles of front of arm. Contents of front of arm were observed. Incidence and percentage of variation in the population was tabulated.
\end{abstract}

Results: Variations in the nerve supply of muscles of front of arm were noticed in $6 \%$ of the cases. In two cadavers (4\%), all the muscles of right arm except coracobrachialis were innervated by a trifurcated branch from Median Nerve (MN) and the latter was supplied by a separate branch from lateral cord. In another left upper limb two separate branches innervated from lateral cord and supplied all the muscles of arm. In the present study, observed variations were more common on right side than on the left side.

Conclusion: Knowledge of such variations are important for the surgeons during surgical exploration of axilla, nerve block in supraclavicular, infraclavicular or axillary region and also during nerve grafting. Also, the study highlights the incidence of variations in a particular region.

\section{INTRODUCTION}

Brachial plexus is formed by the union of the ventral rami of spinal segment C5 to T1, sometimes C4 and T2 may also contribute in the formation of plexus and are called prefixed and postfixed plexus respectively. The branches from brachial plexus supply the upper limb muscles, any variation in the innervation of muscles results in difficulty in diagnosing peripheral neuropathies also knowledge of these variations helps surgeons during nerve blocks and nerve grafts.

Roots arising from the spinal segments form trunks, which bifurcate to form divisions and cords, which in turn continues as peripheral nerves to supply upper limb. Ventral rami of roots C5 and C6 unite to form the upper trunk, C7 forms middle trunk and C8 along with T1, forms the lower trunk. The upper, middle and lower trunk bifurcate to form ventral and dorsal divisions. The dorsal divisions of all the three trunks unite to form posterior cord, further ventral divisions of upper and the middle trunk unite to form the lateral cord whereas the ventral division of lower trunk continues as medial cord [1].

Musculocutaneous Nerve (McN) is a continuation of lateral cord, after giving a twig to shoulder joint, it supplies the muscles of the anterior compartment of the arm and continues as lateral cutaneous nerve of forearm. Fibers from lateral cord and the medial cord unite to form MN in front of axillary artery. At the insertion of coracobrachial is muscle in the arm, Median Nerve (MN) moves from lateral to medial side in front of biceps tendon and enters the forearm through the cubital fossa. MN doesn't give any muscular branches in the arm. Variations in the innervation of muscles of the anterior compartment of arm are common. $\mathrm{McN}$ has frequent variation, it may pierce the Coracobrachialis Muscle (CBM) and run behind it or continue for some distance along with MN and pass behind Biceps Muscle (BBM) or some fibers of MN may pass into
$\mathrm{McN}$ nerve or less frequently MN may send branches to $\mathrm{McN}$ nerve [2]. Absence of $\mathrm{McN}$ is a rare variation. The main aim of the study was to identify any variations in the distribution of nerves in the anterior compartment of arm and explain the clinical implications of these variations during surgical procedures.

\section{MATERIALS AND METHODS}

The present study was a cross-sectional descriptive study, on fifty upper limbs of adults in the age group of 50-90 years, over a period of three years from October 2017 to October 2020 in the Department of Anatomy, Siddhartha Medical College, Vijayawada, Andhra Pradesh. The incisions were given according to the Cunningham's manual [3]. The skin and superficial fascia was removed followed by deep fascia. Muscles of the anterior compartment of arm were identified and cleared. The nerve supply of each muscle was observed and any variations in the innervations of muscles of front of the arm were documented and photographed.

\section{STATISTICAL ANALYSIS}

Descriptive statistics were used, incidence and percentage of variation in the population was tabulated.

\section{RESULTS}

In 50 upper limbs considered, variations were observed in three limbs. In the right upper limb of two adult cadavers, McN was absent. The Coracobrachialis Muscle (CBM) was innervated by a small branch from the lateral cord. MN was formed by the union of lateral and medialcord. After the formation of MN, it trifurcated into three branches at the insertion of CBM. Among the three branches the lateral branch supplied the biceps brachii muscle, middle branch supplied the Brachialis Muscle (BRM) and continued as lateral cutaneous nerve of arm. Medial most branch continued as MN following its normal 
course [Table/Fig-1,2]. As all the flexor muscles of arm are supplied by $\mathrm{MN}$ except CBM any injury or lesion to $\mathrm{MN}$ will cause paralysis of all muscles except CBM. Also, infraclavicular block for any arm surgeries should be given both to median and McN nerve.

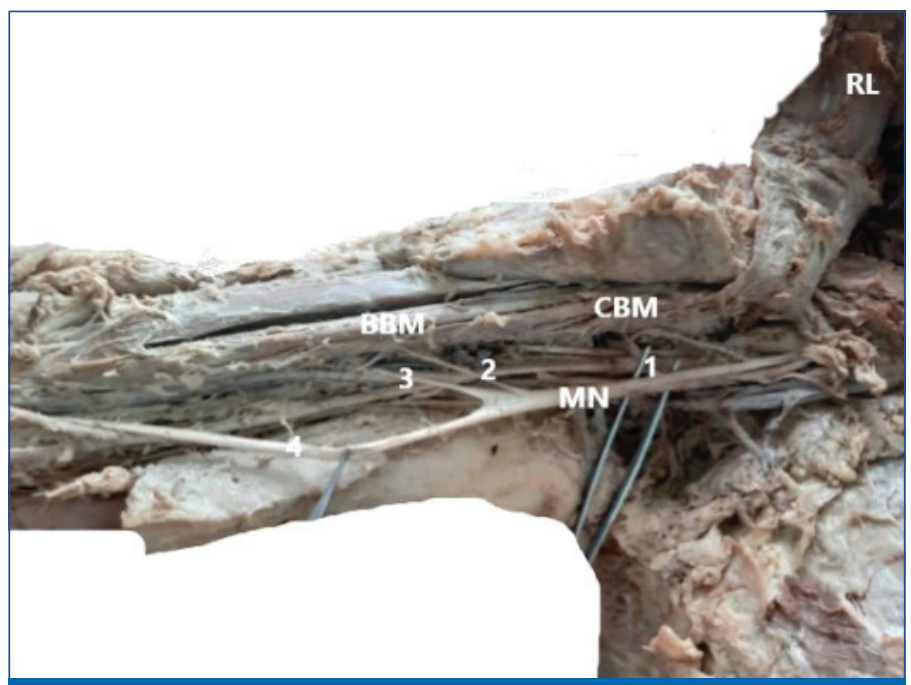

[Table/Fig-1]: Right upper limb where the first branch is arising from the lateral cord and supplying the Coracobrachialis Muscle (CBM) represented by left star. Trifurcation of Median Nerve (MN), represented by right three stars, two branches supplying biceps and Brachialis Muscle (BRM), medial branch continuing as Median Nerve (MN).

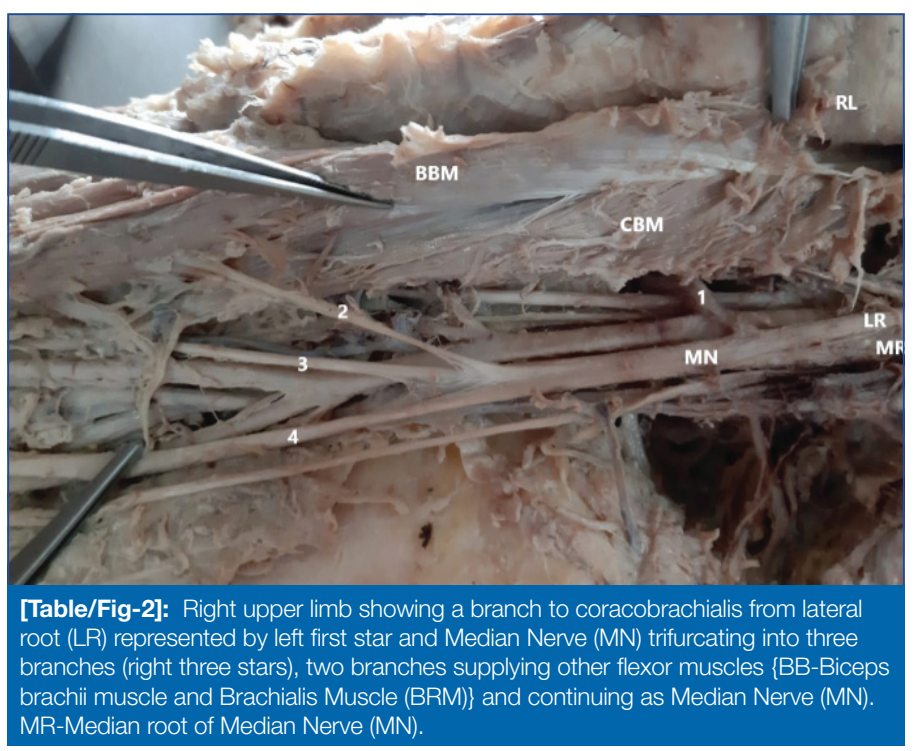

In the left arm of another adult cadaver, it was noticed that the $\mathrm{McN}$ nerve was absent. A small branch was seen coming from the lateral root of $\mathrm{MN}$ to supply the CBM, below that branch there was a communicating branch between lateral and medial root of the MN. Both lateral root and medial root of MN united to form the MN. Before uniting with the medial cord, the lateral root gave a separate branch, which divided in turn into four branches. The first two supplied the two heads of Biceps muscle (BBM), third one supplied to Brachialis Muscle (BRM) and fourth one continued as lateral cutaneous nerve of forearm. The MN divided into two branches before entering the cubital fossa [Table/Fig-3]. In the present case, infraclavicular block should be given to both the branches from the lateral root of the MN.

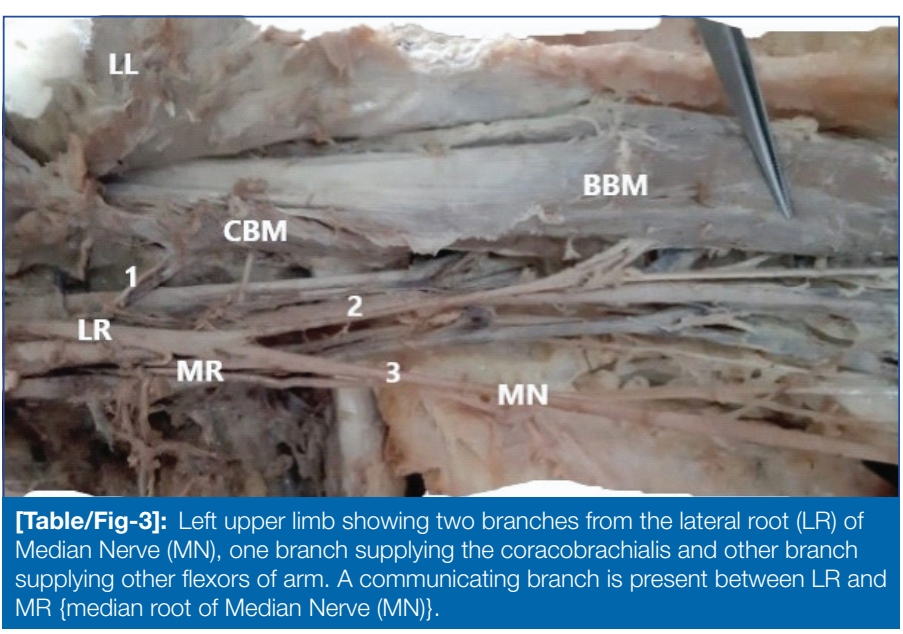

\section{DISCUSSION}

The McN (C5-C7), is a mixed peripheral nerve, arising from the lateral cord of the brachial plexus in the axilla, it runs behind CBM by piercing it [4]. It innervates the muscles of the anterior compartment of the arm and continues as the lateral cutaneous nerve of the forearm. In some cases, the McN may be absent and the muscles of the anterior compartment of the arm receive innervations directly from MN. Variation in the branching pattern of McN nerve and MN have been documented in many studies [Table/Fig-4] [4-8].

Bilateral absence of Musculocutaneous Nerve $(\mathrm{McN})$ was also observed in a study by Bhanu PS and Sankar KD et al., and Raza $K$ et al., $[9,10]$. They reported that muscles of front of arm were supplied by branches from MN except CBM which was supplied by a separate branch from the lateral root of MN. Similarly, in this study a small branch arising from lateral cord and supplying CEM was found. MN was trifurcating and supplying the other muscles of the front of the arm. In another case report two small branches arose from the lateral root of MN, one supplied the CBM and the other branch divided into two to supply two heads of BBM, third branch arose from the $\mathrm{MN}$ and supplied the BRM and continued as lateral cutaneous nerve of the forearm [11].

Similarly, in one of the left upper limbs, it was found that two branches arising from the lateral root, one small branch was supplying the CBM and the other branch supplied all the muscles of the front of the arm by dividing into four branches. The medial root and the lateral root of

\begin{tabular}{|c|c|c|c|c|c|c|}
\hline \multirow[b]{2}{*}{ Authors and years } & \multirow[b]{2}{*}{ Type of study } & \multirow{2}{*}{$\begin{array}{l}\text { Number of limbs } \\
\text { with variation }\end{array}$} & \multicolumn{4}{|c|}{ Muscle innervation and nerve } \\
\hline & & & $\mathrm{McN}$ & CBM & BBM & BRM \\
\hline $\begin{array}{l}\text { Budhiraja V et al., } \\
\text { (2016) [4] }\end{array}$ & $\begin{array}{l}\text { Original review with } \\
116 \text { upper limbs }\end{array}$ & 13 & $\begin{array}{l}\text { Absent in } 13 \\
\text { limbs }\end{array}$ & $\begin{array}{l}\text { Six limbs with innervation from lateral } \\
\text { root and others from Median nerve }\end{array}$ & Median nerve in all 13 limbs & Median nerve \\
\hline $\begin{array}{l}\text { Nagwani M et al., } \\
\text { (2014) [5] }\end{array}$ & Case report & 1 & Present & $\mathrm{McN}$ & $\mathrm{McN}$ & $\mathrm{McN}$ \\
\hline $\begin{array}{l}\text { Sarkar A and Saha } \\
\text { A, (2014) [6] }\end{array}$ & Case report & 2 & $\begin{array}{l}\text { Absent in both } \\
\text { limbs }\end{array}$ & Lateral root & $\begin{array}{c}\text { In one limb from lateral cord } \\
\text { and other limb from Median } \\
\text { nerve }\end{array}$ & Median nerve \\
\hline $\begin{array}{l}\text { Kaur P et al., (2014) } \\
\text { [7] }\end{array}$ & $\begin{array}{c}\text { Original review with } \\
30 \text { limbs }\end{array}$ & 4 & $\begin{array}{l}\text { Absent in four } \\
\text { limbs }\end{array}$ & $\begin{array}{c}\text { In one limb CBM was innervated } \\
\text { by lateral root and other limbs by } \\
\text { median nerve }\end{array}$ & Median nerve & Median nerve \\
\hline $\begin{array}{l}\text { Jayagandhi S et al., } \\
\text { (2018) [8] }\end{array}$ & Case report & 3 & Absent & Median nerve & Median nerve & Median nerve \\
\hline Present study & $\begin{array}{l}\text { Original study with } \\
50 \text { limbs }\end{array}$ & 3 & Absent & Lateral root & Median nerve & Median nerve \\
\hline
\end{tabular}

[Table/Fig-4]: Literature review with comparison of anomalous innervation of musculocutaneous and Median Nerve (MN) [4-8]

McN: Musculocutaneous nerve; CBM: Coracobrachialis muscle; BBM: Biceps muscle; BRM: Brachialis muscle 
median were connected by a communication between them. Le Minor $\mathrm{JM}$, has classified the variations into five types, type I with separate median and $\mathrm{McN}$ nerve, type II where fibers of medial root continue with $\mathrm{McN}$ and join $\mathrm{MN}$ at the middle of arm, type III where fibers of lateral root continue with $\mathrm{McN}$ and in the middle of arm leave it and join with $\mathrm{MN}$, type IV where $\mathrm{McN}$ and $\mathrm{MN}$ continue as single nerve and in the middle of arm McN separates and supplies the flexor muscles of arm, type $\mathrm{V}$ where branches of McN directly arises from the MN [12].

According to this classification, the two right upper limbs correspond to type $\mathrm{V}$ but not completely as branch to CBM is separate and arising from lateral root. In case of left upper limb, it is almost similar to type I, with two separate branches from lateral root of MN with one thin branch from lateral root supplying CBM. Another branch, arising below it from the lateral cord, giving muscular branches to the remaining flexor muscles of arm and continuing as lateral cutaneous nerve of forearm. This study has some limitation with small sample size, but the results add to the incidence of variations in the south Indian population.

The formation of upper limb bud starts at 26-27days whereas, the brachial plexus become evident at 34-35 days with the growth cones of motor axons entering the limb bud. The forelimb muscles are formed during the fifth week and attains adult pattern within 4648 days [13]. Brachial plexus help in distribution from several spinal segments and single spinal segment can supply through several peripheral nerves [14]. The development of forelimb muscles is by expression of five Hoxd genes from the mesenchyme of the paraxial mesoderm [15]. The growth cones of the axons are guided by the highly sight specific expression and fission by the chemoattractants and chemorepulsants. The chemoattractants like neurotropic growth factor, c-kit ligand. Neutrin-1, neutrin-2 etc., support and attract the growth cones of the axons [16]. Any variation in the division or distribution of the nerves results due to abnormal signaling between mesenchymal cells and the growth cones of the developing axons during the time of fission.

Clinical implications associated with this variation are if there is any lesion or injury affecting the roots C5, C6 and C7, it results in paralysis/paresis of flexor muscles of arm and some of major muscles of forearm as both lateral root and $\mathrm{McN}$ will be affected. Any lesion affecting both $\mathrm{MN}$ and $\mathrm{McN}$ will affect all flexors of arm and forearm. In the present study, as the McN was absent in two cases and CBM alone was supplied by individual branch from lateral cord, any injury to MN alone will cause paralysis of all flexors of arm and forearm except CBM. So, a thorough knowledge of the variation in the innervation of muscles of the arm is essential for the surgeons and clinicians.

\section{Limitation(s)}

Limitations of the present study was small sample size, so further studies need to be done with larger sample size to estimate the incidence of variations in different race and ethnic groups, with radiological correlation of ultrasound guided identification of variation.

\section{CONCLUSION(S)}

Variation in 6\% of cases, with absence of McN nerve in two limbs and innervation of all flexors of arm by MN except CBM was observed. In another arm, McN was absent and two separate branches from lateral root were supplying the flexors of arm. Knowledge about nerve variations helps in correlating and in preventing any iatrogenic injuries during shoulder dislocations, traumatic injuries or any shoulder reconstruction surgeries. Also, knowledge of these variations helps to explain unexplained clinical symptoms during regional anaesthesia and nerve conduction studies.

\section{REFERENCES}

[1] Standring S, editor. Gray's Anatomy. $40^{\text {th }}$ edition. Philadelphia: Elsevier Churchill Livingstone; 2008. Pp. 803-05.

[2] Moore KL, Dalley AF. Clinically oriented anatomy. $6^{\text {th }}$ ed. Philadelphia: Lippincott Williams \& Wilkins; 1999. 737-38.

[3] Romanes GJ. Cunningham's Manual of Practical Anatomy. London, Oxford University Press. $15^{\text {th }}$ edition 1986.

[4] Budhiraja V, Rastogi R, Asthana AK, Sinha P, Krishna A, Trivedi V. Concurrent variations of median and musculocutaneous nerves and their clinical correlation-a cadaveric study. Italian Journal of Anatomy and Embryology. 2011;116(2):67-72.

[5] Nagwani M, Rani A, Rani A, Chopra J, Srivastava AK, Sharma PK. A Variant Course of Lateral Root of Median Nerve: Embryological Basis. Asian J Med Sci. 2014;5(2):146-50.

[6] Sarkar A, Saha A. Bilateral absence of musculocutaneous nerve: A case report. J Clin Diagn Res. 2014;8(9):AD06.

[7] Kaur P, Kumar R, Jain A. Variations in innervation of muscles in anterior compartment of arm-A cadaveric study. J Clin Diagn Res. 2014;8(5):AC01.

[8] Jayagandhi S, Rajasegaran R, Verma S, Nim VK. Bilateral absence of musculocutaneous nerve: Report of two cases. Int J Anat Res. 2018;6(2.1):511013. Doi: $10.16965 /$ ijar.2018.132.

[9] Bhanu PS, Sankar KD. Bilateral absence of musculocutaneous nerve with unusual branching pattern of lateral cord and median nerve of brachial plexus. Anat Cell Biol. 2012;45(3):207.

[10] Raza K, Singh S, Rani N, Mishra R, Mehta K, Kaler S. Anomalous innervation of the median nerve in the arm in the absence of the musculocutaneous nerve. Sultan Qaboos Univ Med J. 2017;17(1):e106.

[11] Beheiry EE. Anatomical variations of the median nerve distribution and communication in the arm. Folia Morphol. 2004;63(3):313-18.

[12] Le Minor JM. A rare variation of the median and musculocutaneous nerves in man. Arch Anat Histol Embryol. 1990;73:33-42.

[13] Moore KL, Parsaud TVN. The Developing Human. Clinically Oriented Embryology. Philadelphia, Saunders. 7th edition 2004; 408-23.

[14] Sinnatamby CS. Last's Anatomy. Regional and Applied. New York, Churchill Livingstone Elsevier. 11 $1^{\text {th }}$ edition 2008; 1-34.

[15] Morgan BA, Tabin C. Hox genes and growth: Early and late roles in limb bud morphogenesis. Development. 1994;181-86.

[16] Larsen WJ. Human Embryology. Edinburg, Churchill Livingstone, $2^{\text {nd }}$ edition. 1997; 311-39.

\section{PARTICULARS OF CONTRIBUTORS:}

1. Assistant Professor, Department of Anatomy, Government Siddhartha Medical College, Vijayawada, Andhra Pradesh, India.

2. Senior Resident, Department of Anatomy, All India Institute of Medical Sciences, Hyderabad, Telangana, India.

3. Assistant Professor, Department of Anatomy, Government Siddhartha Medical College, Vijayawada, Andhra Pradesh, India.

4. Assistant Professor, Department of Anatomy, Government Siddhartha Medical College, Vijayawada, Andhra Pradesh, India.

5. Professor and Head, Department of Anatomy, Government Siddhartha Medical College, Vijayawada, Andhra Pradesh, India.

NAME, ADDRESS, E-MAIL ID OF THE CORRESPONDING AUTHOR:

P Sushma Rao,

E-mail: sushma.poleneni@gmail.com
All India Institute of Medical Sciences, Bibinagar, Hyderabad, Telangana, India.
PLAGIARISM CHECKING METHODS: [Jain H et al.]

- Plagiarism X-checker: Feb 24, 2021

- Manual Googling: May 12, 2021

- iThenticate Software: May 13, $2021(18 \%)$
ETYMOLOGY: Author Origin

\section{AUTHOR DECLARATION:}

- Financial or Other Competing Interests: None

- Was Ethics Committee Approval obtained for this study? No

- Was informed consent obtained from the subjects involved in the study? NA

- For any images presented appropriate consent has been obtained from the subjects. NA
Date of Submission: Feb 23, 2021 Date of Peer Review: Mar 28, 2021 Date of Acceptance: May 13, 2021 Date of Publishing: Oct 01, 2021 